\title{
Approximation of Alternating Series using Correction Function and Error Function
}

\author{
Kumari Sreeja S Nair \\ Assistant Professor of Mathematics \\ Govt.Arts College, Thiruvananthapuram, \\ Kerala, India
}

\author{
Dr.V.Madhukar Mallayya \\ Former Professor and Head \\ Department of Mathematics \\ Mar Ivanios College Thiruvananthapuram, India
}

\begin{abstract}
In this paper we give a rational approximation of an alternating series using remainder term of the series. For that we shall introduce a correction function to the series. The correction function plays a vital role in series approximation. Using correction function we shall deduce an error function to the series.
\end{abstract}

Keywords: Correction function, error function, remainder term, alternating series, Madhava series, rational approximation.

\section{INTRODUCTION}

In $14^{\text {th }}$ century, the Indian mathematician Madhava gave an approximation of the pi series using remainder term of the series.

Madhava series is,

$\mathrm{C}=\frac{4 d}{1}-\frac{4 d}{3}+\frac{4 d}{5}-\cdots \cdots \cdots \cdots \cdots \cdots \cdots \cdots+(-1)^{n-1} \frac{4 d}{2 n-1}+(-1)^{n} \frac{4 d(2 n) / 2}{(2 n)^{2}+1}$, where $\mathrm{C}$ is the circumference of a circle of diameter $d$. Here the remainder term is $(-1)^{n} 4 d_{n} G_{n}$ where $G_{n}=\frac{(2 n) / 2}{(2 n)^{2}+1}$ is the correction function. The introduction of the correction term gives a better approximation of the series.

\section{METHOD}

\section{APPROXIMATION OF THE ALTERNATING SERIES $\sum_{n=1}^{\infty} \frac{(-1)^{n-1}}{n(n+1)(n+2)}$}

The alternating series $\sum_{n=1}^{\infty} \frac{(-1)^{n-1}}{n(n+1)(n+2)}$ satisfies the conditions of alternating series test and so it is convergent.

If $R_{n}$ denotes the remainder term after $n$ terms of the series, then

$\mathrm{R}_{\mathrm{n}}=(-1)^{n} \mathrm{G}_{\mathrm{n}}$ where $\mathrm{G}_{\mathrm{n}}$ is the correction function after $\mathrm{n}$ terms of the series

Theorem:

The correction function for the alternating series $\quad \sum_{n=1}^{\infty} \frac{(-1)^{n-1}}{n(n+1)(n+2)}$ is

$\mathrm{G}_{\mathrm{n}}=\frac{1}{2 n^{3}+9 n^{2}+\frac{29}{2} n+\frac{33}{4}}$

Proof:

If $G_{n}$ denotes the correction function after $n$ terms of the series, then

we have $\mathrm{G}_{\mathrm{n}}+\mathrm{G}_{\mathrm{n}+1}=\frac{1}{(n+1)(n+2)(n+3)}$ 
The error function is $\mathrm{E}_{\mathrm{n}}=\mathrm{G}_{\mathrm{n}}+\mathrm{G}_{\mathrm{n}+1}-\frac{1}{(n+1)(n+2)(n+3)}$

For $r_{1}, r_{2} r_{3} \in \mathrm{R}$ and for any fixed $\mathrm{n}$,

Let $\mathrm{G}_{\mathrm{n}}\left(\mathrm{r}_{1}, \mathrm{r}_{2}, \mathrm{r}_{3}\right)=\frac{1}{2 n^{3}+12 n^{2}+22 n+12-\left(r_{1} n^{2}+r_{2} n+r_{3}\right)}$

Then the error function is

$\mathrm{E}_{\mathrm{n}}\left(\mathrm{r}_{1}, \mathrm{r}_{2}, \mathrm{r}_{3}\right)=\mathrm{G}_{\mathrm{n}}\left(\mathrm{r}_{1}, \mathrm{r}_{2}, \mathrm{r}_{3}\right)+\mathrm{G}_{\mathrm{n}+1}\left(\mathrm{r}_{1}, \mathrm{r}_{2}, \mathrm{r}_{3}\right)-\frac{1}{(n+1)(n+2)(n+3)}$ is a rational function of $\mathrm{r}_{1}$, $\mathrm{r}_{2}$ and $\mathrm{r}_{3}$.

ie $\quad E_{n}\left(r_{1}, r_{2}, r_{3}\right)=\frac{N_{n}\left(r_{1}, r_{2}, r_{3}\right)}{D_{n}\left(r_{1}, r_{2}, r_{3}\right)}$

$D_{n}\left(r_{1}, r_{2}, r_{3}\right) \approx 4 n^{9}$ is a maximum for large $\mathrm{n}$.

$\left|N_{n}\left(r_{1}, r_{2}, r_{3}\right)\right|$ is minimum for $r_{1}=3, r_{2}=\frac{15}{2}, r_{3}=\frac{15}{4}$

$\operatorname{So}\left|E_{n}\left(r_{1}, r_{2}, r_{3}\right)\right|$ is minimum for $r_{1}=3, r_{2}=\frac{15}{2}, r_{3}=\frac{15}{4}$

Thus for $r_{1}=3, r_{2}=\frac{15}{2}, r_{3}=\frac{15}{4}$, we have both $\mathrm{G}_{\mathrm{n}}$ and $\mathrm{E}_{\mathrm{n}}$ are functions of a single variable $\mathrm{n}$.

That is the correction function for the series $\quad \sum_{n=1}^{\infty} \frac{(-1)^{n-1}}{n(n+1)(n+2)}$ is

$\mathrm{G}_{\mathrm{n}}=\frac{1}{2 n^{3}+9 n^{2}+\frac{29}{2} n+\frac{33}{4}}$

The absolute value of the error function is

$\left|\mathrm{E}_{\mathrm{n}}\right|=\frac{\left|\frac{27}{4} n^{2}+27 n+\frac{423}{16}\right|}{\left(2 n^{3}+9 n^{2}+\frac{29}{2} n+\frac{33}{4}\right)\left(2 n^{3}+15 n^{2}+\frac{77}{2} n+\frac{135}{4}\right)\{(n+1)(n+2)(n+3)\}}$

Hence the theorem.

\section{RESULTS AND DISCUSSIONS}

For the series $\sum_{n=1}^{\infty} \frac{(-1)^{n-1}}{n(n+1)(n+2)}$,

(1) The correction function is $G_{n}=\frac{1}{2 n^{3}+9 n^{2}+\frac{29}{2} n+\frac{33}{4}}$

(2) The magnitude of error function is

$$
\left|\mathrm{E}_{\mathrm{n}}\right|=\frac{\left|\frac{27}{4} n^{2}+27 n+\frac{423}{16}\right|}{\left(2 n^{3}+9 n^{2}+\frac{29}{2} n+\frac{33}{4}\right)\left(2 n^{3}+15 n^{2}+\frac{77}{2} n+\frac{135}{4}\right)\{(n+1)(n+2)(n+3)\}}
$$

(3) Clearly $\mathrm{G}_{\mathrm{n}}<\frac{1}{(n+1)(n+2)(n+3)}$, the absolute value of the $(\mathrm{n}+1)^{\text {th }}$ term.

\section{CONClusion}

The correction function and error function play a vital role in series approximation. We can improve the accuracy of the sum of the series using these functions.

\section{REFERENCES}

[1] Dr. Konrad Knopp- Theory and Application of Infinite series - Blackie and son limited (London and Glasgow)

[2] Sankara and Narayana, Lilavati of Bhaskaracharya with the Kriyakramakari, an elaborate exposition of the rationale with introduction and appendices (ed) K.VSarma (Visvesvaranand Vedic Research Intittute, Hoshiarpur) 1975, p, 386-391. 
[3] Dr. V.Madhukar Mallayya - Proceedings of the Conference on Recent Trends in Mathematical Analysis-(O 2003, llied Publishers Pvt.Ltd, ISBN 81 -7764-399-1

[4] A course of Pure Mathematics - G.H.Hardy (tenth edition) Cambridge at the university press 1963

[5] K. Knopp, Infinite sequences. and series, Dover- 1956

[6] T. Hayashi,. K. Kusuba and M. Yano, Centaururs, 33, 149, 1990

[7] Yuktidipika of Sankara (commentary on Tantrasangraha), ed.K.V.Sarma, Hoshiarpur 1977 